\title{
CAPÍTULO 51: RESÍDUOS DE ALIMENTOS COMO FONTE DE COMPOSTOS ANTIMICROBIANOS - UMA REVISÃO E DISCUSSÃO DO POTENCIAL
}

\author{
CHAPTER 51: FOOD RESIDUES AS SOURCE OF ANTIMICROBIAL \\ COMPOUNDS - A REVIEW AND DISCUSSION OF POTENTIALS
}

\author{
Nataís Fleck ${ }^{1}$;Wemerson Castro de Oliveira ${ }^{2}$; Hans Fröder ${ }^{3}$; Voltaire Sant'Anna ${ }^{4}$
}

\begin{abstract}
Resumo
A busca por substâncias que possam ser utilizadas como conservadores alimentares, naturais, não-tóxicas e que não interfiram nas características organolépticas dos produtos são uma preocupação e um desafio para a indústria de alimentos. $\mathrm{O}$ objetivo deste estudo foi analisar referências bibliográficas sobre a utilização de resíduos da indústria como fonte de compostos antimicrobianos, seu modo de ação, as possíveis aplicações e limitações para aplicações em alimentos. Observou-se que em vários trabalhos empregando extratos vegetais, destacam os polifenóis e óleos essenciais como alternativas viáveis para a conservação e aumento da vida de prateleira. Estes estudos têm recebido ênfase para a melhoria da qualidade na indústria de alimentos principalmente por terem ação antimicrobiana, uma vez que interagem com a membrana celular. Constata-se que as pesquisas provenientes de compostos de origem natural, que possam substituir os aditivos sintéticos, necessitam considerar processos de degradação (oxigênio, luz, enzimas) ao longo do período de armazenamento, aspectos toxicológicos e equipamentos para escalonar o processo. O desenvolvimento de soluções sustentáveis para a gestão de resíduos alimentares ainda permanece sendo um dos principais desafios da sociedade.
\end{abstract}

Palavras-Chave: Rejeitos agroindustriais, Atividade antimicrobiana, Bioconservantes, Polifenóis, Óleos essenciais.

\begin{abstract}
The search for substances that can be used as food preservatives, natural, non-toxic and that do not interfere with the organoleptic characteristics of products is a concern and a challenge for the food industry. The aim of this study was to analyze bibliographic references on the use of industry residues as a source of antimicrobial compounds, their mode of action, possible applications and limitations for applications in food. It was observed that in several studies using plant extracts, polyphenols and essential oils are highlighted as viable alternatives for the conservation and increase of shelf life. These studies have received emphasis on improving quality in the food industry, mainly because they have antimicrobial action, since they interact with the cell membrane. It appears that research from compounds of natural origin, which can replace synthetic additives, needs to consider degradation processes (oxygen, light, enzymes) throughout the storage period, toxicological aspects and equipment to scale the process. The development of sustainable solutions for the management of food waste still remains one of the main challenges facing society.
\end{abstract}

Keywords: Agro-industrial waste, Antimicrobial activity, Biopreservatives, Polyphenols, essential oils.

\footnotetext{
${ }^{1}$ Mestranda Profissional em Ciência e Tecnologia de Alimentos, Universidade Estadual do Rio Grande do Sul (UERGS), natais-fleck@uergs.edu.br

${ }^{2}$ Doutor em Microbiologia Agrícola, Instituto Federal de Educação, Ciência e Tecnologia Sul-rio-grandense (IFSul),wemersonoliveira@ifsul.edu.br

${ }^{3}$ Doutor em Ciência dos Alimentos, Universidade do Vale do Taquari (UNIVATES), hfroder@hotmail.com

${ }^{4}$ Doutor em Engenharia Química, Universidade Estadual do Rio Grande do Sul (UERGS), voltairesantanna@uergs.edu.br
} 


\section{Introdução}

A pesquisa por conservantes naturais para aplicação em alimentos tem sido impulsionada pela demanda do consumidor por produtos sem ou com redução de compostos químicos, mas que se mantenham seguros, que tenham alta qualidade e uma longa vida útil. Além disso, o surgimento e proliferação de microrganismos patógenos tem se mostrado um sério problema de saúde pública no mundo e, assim, esforços em várias áreas das ciências da vida e da saúde têm sido realizados para estudar e controlar esse problema (KHORSHIDIAN et al., 2018). Neste contexto, a busca por substâncias que possam ser utilizadas como conservadores alimentares, não-tóxicas e que não interfiram nas características organolépticas (LUCERA et al., 2012) dos produtos finais são preocupação constante e um dos desafios atuais mais importantes na indústria de alimentos (KHORSHIDIAN et al., 2018). Diante de toda essa demanda e aliado também a uma visão sustentável, surgem as pesquisas com os resíduos orgânicos sólidos.

Resíduos orgânicos sólidos da indústria de alimentos têm sido estudados como fonte natural de polifenóis, carotenóides, fibras, compostos com capacidade antimicrobiana, antioxidante, anti-hipertensiva, anticâncer e pigmentos. Além disso, apresentam potencial claro a ser processado pelas indústrias de alimentos e acostumado à dieta humana (ZHU et al., 2015; DALLA COSTA et al., 2016; NAGY et al., 2017). Considerando essas importantes propriedades, extratos vegetais já vêm sendo estudados como agentes antimicrobianos. Matrizes alimentares com concentrações altas de polifenóis e compostos derivados atuam como inibidores bacterianos e fúngicos, fungos filamentosos e leveduras, importantes para a cadeia agroindustrial (CAXAMBÚ et al., 2016; SANT'ANNA et al., 2017; TROJAIKE et al., 2018; GIRARDI et al., 2019)

Novos estudos vêm sendo publicados na literatura científica sobre o assunto e é importante que se mantenha a análise dos dados gerados sobre as diferentes matrizes propostas, modos de ação e suas aplicações. Ainda, a discussão de barreiras para a real aplicação desses compostos na indústria de alimentos também deve ser foco de observação para que haja avanços em pesquisa aplicada na área. Assim, o objetivo do presente trabalho é analisar dados de artigos científicos atuais sobre a utilização de resíduos da indústria de alimentos como fonte de compostos antimicrobianos, seu modo de ação, as possíveis aplicações em alimentos e discutir limitações em potenciais para o emprego real em aplicações de alimentos. Para tanto, artigos científicos, teses, dissertações e documentos técnicos, a partir de busca em plataformas com uma ampla base de dados e de palavras-chaves, foram analisadas criteriosamente e discutidas no âmbito proposto. 


\section{Desenvolvimento}

Resíduos e subprodutos da cadeia produtiva de alimentos são fontes disponíveis e baratas de compostos com importantes atividades para aplicações em alimentos. Atualmente, em sua grande maioria são descartados ou conduzidos à compostagem, ignorando-se o grande potencial que apresentam de gerarem produtos de alto valor agregado e que podem se inserir no contexto de economia circular, uma das grandes tendências mundiais para o setor alimentício. Dentre as estratégias de extração de compostos de alto valor agregado, estão aqueles com potencial de serem utilizados como bioconservantes. A Figura 1 indica a tendência de pesquisas sobre o tema atualmente. Apesar dos resultados não mostrarem apenas trabalhos que lidam diretamente com a temática, mas também documentos com essas palavras-chave no texto, é clara a curva em ascensão na busca por compostos antimicrobianos a partir de subprodutos ou descartes de alimentos nos último cinco anos.

Figura 1. Número de citações em procura abrangente no Google Scholar (azul, no eixo principal) e Science Direct (vermelho, no eixo secundário) por food by-products antimicrobial.

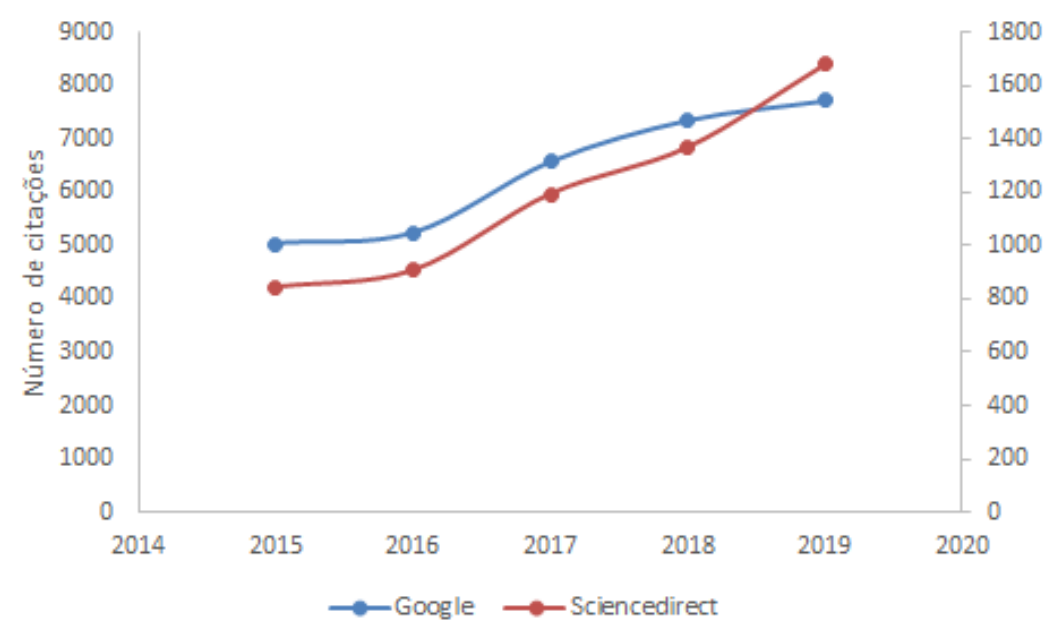

O Quadro 1 relaciona alguns estudos que utilizaram matrizes alimentares a partir do processamento de alimentos como fonte de compostos naturais para a inibição de microrganismos.

Como observado no Quadro 1, são várias as matrizes que têm sido estudadas como fonte de compostos naturais com potencial antimicrobiano. Friedman, Henika e Levin (2013) observaram propriedades inibitórias de bagaço de azeitona usando um ensaio quantitativo de atividade bactericida contra patógenos de origem alimentar como E. coli, L. monocytogenes, $S$. enterica e S. aureus. Já Zambrano (2019), concluiu que os extratos de resíduos de uva, maçã e pitaia podem ser bons candidatos ao desenvolvimento de conservantes naturais, por ter observado em seu estudo a inibição de biofilmes de P. aeruginosa, P. putida e S. aureus. 
FLECK, et al.

Quadro 1. Resumo da utilização de extratos de resíduos de alimentos com atividade antimicrobiana

\begin{tabular}{|c|c|c|c|c|}
\hline Resíduo & Extração & Compostos identificados/sugeridos & Microrganismo testado* & Referência \\
\hline $\begin{array}{l}\text { Bagaço de cana-de- } \\
\text { açúcar }\end{array}$ & $\begin{array}{l}\text { Aquosa a quente } \\
\qquad\left(10 \mathrm{~kg} / \mathrm{m}^{3}\right)\end{array}$ & $\begin{array}{c}\text { Polifenóis totais, flavonóides, compostos } \\
\text { com atividade sequestrante de radicais } \\
\text { ABTS e DPPH }\end{array}$ & $\begin{array}{c}\text { Staphylococcus aureus (-), Listeria monocytogenes (-), } \\
\text { Escherichia coli (-), Salmonella Enteritidis (-) }\end{array}$ & $\begin{array}{l}\text { Girardi et al., } \\
\text { (2019) }\end{array}$ \\
\hline $\begin{array}{l}\text { Casca de limão, laranja } \\
\text { e cidra }\end{array}$ & $\begin{array}{l}\text { Aquosa a quente (micro- } \\
\text { ondas) }\end{array}$ & n.i. & $\begin{array}{c}\text { E. coli (-), Pseudomonas fluorescens (-), Pseudomonas putida (- } \\
\text { ), Staphylococcus epidermidis (-) }\end{array}$ & $\begin{array}{l}\text { Caputo et al. } \\
\quad(2018)\end{array}$ \\
\hline $\begin{array}{l}\text { Casca de pinhão } \\
\text { (Araucaria } \\
\text { angustifoglia) }\end{array}$ & $\begin{array}{l}\text { Aquosa a quente } \\
\qquad\left(10 \mathrm{~kg} / \mathrm{m}^{3}\right)\end{array}$ & n.i. & $\begin{array}{c}\text { S.aureus }(+), \text { Bacillus cereus }(+), \text { L.monocytogenes }(+), \text { Listeria } \\
\text { innocua }(+), \text { Aeromonas hydrophila }(+), \text { E.coli }(-), \text { S. Enteritidis } \\
(-), \text { Pseudomonas aeruginosa }(-), \text { Corynebacterium fimi }(-), \\
\text { fungos fitopatogênicos }(-)\end{array}$ & $\begin{array}{l}\text { Trojaike et al. } \\
\qquad(2018)\end{array}$ \\
\hline $\begin{array}{l}\text { Acerola verde } \\
\text { (Malpighia } \\
\text { maraginata) }\end{array}$ & Aquosa (ultrassom) & $\begin{array}{l}\text { Polifenóis, vitamina } \mathrm{C} \text { e atividade } \\
\text { antioxidante }\end{array}$ & Fungos filamentosos (-), Candida albicans (+), S. aureus (+) & Rocha (2019) \\
\hline Borra de café & Aquosa $\left(10 \mathrm{~kg} / \mathrm{m}^{3}\right)$ & $\begin{array}{l}\text { Polifenóis totais, compostos com } \\
\text { atividade sequestrante de radicais ABTS } \\
\text { e DPPH e poder quelante de ferro }\end{array}$ & $\begin{array}{l}\text { S.aureus (-), B.cereus (-), L.monocytogenes (-), L.innocua (-), } \\
\text { Aeromonas hydrophila (-), E.coli (-), S. Enteritidis (-), P. } \\
\text { aeruginosa (-), C. fimi (-), fungos fitopatogênicos (-) }\end{array}$ & $\begin{array}{l}\text { Sant'Anna et al. } \\
\text { (2017) }\end{array}$ \\
\hline $\begin{array}{c}\text { Jabuticaba (Myrciaria } \\
\text { cauliflora) }\end{array}$ & $\begin{array}{l}\text { Aquosa e } \\
\text { microencapsulado }\end{array}$ & Compostos fenólicos (antocianinas) & S. aureus $(+)$, E. coli $(+), S$. Enteritidis $(+)$ & Baldin (2016) \\
\hline $\begin{array}{l}\text { Casca, polpa e } \\
\text { biomassa do noni in } \\
\text { natura }\end{array}$ & Éter e álcool etílico & n.i. & $\begin{array}{c}\text { S. aureus }(+), \text { L. monocytogenes }(+), \text { E. coli }(+), \text { Salmonella } \\
\text { Choleraesuis }(+)\end{array}$ & $\begin{array}{l}\text { Farias et al. } \\
\quad(2018)\end{array}$ \\
\hline Casca de noz-pecã & Aquosa $\left(10 \mathrm{~kg} / \mathrm{m}^{3}\right)$ & n.i. & $\begin{array}{l}\text { S.aureus }(+), \text { B.cereus }(+), \text { L.monocytogenes }(+), \text { L.innocua }(+), \\
\text { Aeromonas hydrophila }(+), \text { E.coli }(-), S \text {. Enteritidis }(+), P . \\
\text { aeruginosa }(+), \text { C. fimi }(-), \text { fungos fitopatogênicos }(-)\end{array}$ & $\begin{array}{l}\text { Caxambú et al. } \\
\text { (2016) }\end{array}$ \\
\hline $\begin{array}{c}\text { Casca de mirtilo } \\
\text { (Vaccinium myrtillus) }\end{array}$ & $\begin{array}{l}\text { Aquosa, acetona, metanol } \\
\text { e etanol }(40 \%, 50 \% \\
60 \%, 70 \% \text { e } 80 \%)\end{array}$ & Antocianinas & $\begin{array}{c}\text { S.aureus }(+), \text { B.cereus }(+), \text { B.subtilis }(+), \text { Enterococcus faecalis } \\
(+), \text { P.aeruginosa }(+), \text { E. coli }(+), \text { Serratia marcensces, } S . \\
\text { Enteritidis }(+)\end{array}$ & $\begin{array}{c}\text { Santos e Santana } \\
\text { (2016) }\end{array}$ \\
\hline
\end{tabular}




\begin{tabular}{|c|c|c|c|c|}
\hline Resíduo & Extração & $\begin{array}{c}\text { Compostos } \\
\text { identificados/sugeridos }\end{array}$ & Microrganismo testado* & Referência \\
\hline $\begin{array}{l}\text { Polpa do jatobá (Hymenaea } \\
\text { courbaril), polpa, casca e semente } \\
\text { do tamarindo (Tamarindus indica } \\
\text { L.), folha de bananeira (Musa } \\
\text { spp.), folha de jabuticabeira } \\
\text { (Plinia cauliflora), folha de Ora- } \\
\text { pro-nóbis (Pereskia aculeata), } \\
\text { estigmas de milho (Zea mays), pó } \\
\text { torrado de café (Coffea arabica) }\end{array}$ & Metanol & Compostos fenólicos & $\begin{array}{l}\text { B.cereus }(+), \text { S.aureus }(+), \text { E.coli }(+), \text { P.aeruginosa }(+) \text {, } \\
\text { S.Typhimurium }(+), S . \text { Enteritidis }(+), \text { Shigella sonnei }(+)\end{array}$ & Alvarenga (2018) \\
\hline $\begin{array}{l}\text { Bolo de azeitona e água residual } \\
\text { da azeitona }\end{array}$ & $\begin{array}{c}\text { Etanol } \\
\text { teor de fenol do resíduo } \\
\text { sólido }(8,90 \pm 0,728 \mathrm{~g} / \mathrm{L} \\
\text { e do resíduo líquido } 0,95 \\
\pm 0,017 \mathrm{mg} / \mathrm{g})\end{array}$ & Polifenóis & S. aureus (+),Streptococcus faecalis (-), E. coli (-) & Leouifoudi et al. (2015) \\
\hline $\begin{array}{l}\text { Óleo essencial de orégano e } \\
\text { extrato de resíduo de abóbora }\end{array}$ & Etanol & n.i. & $\begin{array}{l}\text { Coliforms }(+), \text { Mesófilos }(+), \text { Salmonella }(+) \\
\text { E. coli }(+), \text { S. aureus }(+), \text { L. monocytogenes }(+)\end{array}$ & Caetano et al. (2017) \\
\hline $\begin{array}{l}\text { Casca de limão, tangerina e } \\
\text { laranja }\end{array}$ & $\begin{array}{l}\text { Aquosa (ultra alta } \\
\text { pressão) }\end{array}$ & $\begin{array}{l}\text { Polifenóis totais, } \\
\text { compostos com atividade } \\
\text { sequestrante de radicais } \\
\text { ABTS e DPPH }\end{array}$ & $\begin{array}{c}\text { E. faecalis }(+), \text { B.subtilis }(+), \text { S. aureus }(+), \text { Clostridium } \\
\text { sporogenes }(+), \text { Klebsiella }(-), \text { S. Typhimurium }(+), \\
\text { Acinetobacter lwoffii }(+), \text { A. junii }(+), \text { linhagens de } \\
\text { L.monocytogenes }(-)\end{array}$ & Casquete et al. (2015) \\
\hline
\end{tabular}

* (-) sem inibição; (+) inibição; n.i. não identificada 
Extrato da casca de noz-pecã também apresentou atividade antibacteriana, na concentração de $10 \mathrm{~kg} / \mathrm{m}^{3}$, contra A. hydrophila, S. aureus, B. cereus, L. monocytogenes, L. inoccua, S. Enteritidis e P. aeruginosa. No entanto, o extrato aquoso não apresentou capacidade de inibir o crescimento de Corynebacterium spp., Clostridium perfringens e Escherichia coli. Além disso, os autores verificaram que o extrato, quando foi aplicado em folhas de alface, se mostrou eficaz na redução da contagem de bactérias mesófilas e psicrotróficas ao longo de 5 dias de armazenamento do produto em temperatura de refrigeração, indicando grande potencial para ser utilizado como antimicrobiano natural para aplicações em alimentos (CAXAMBÚ et al., 2016). Trojaike e colaboradores (2018) observaram que extrato aquoso de casca de pinhão na concentração de $10 \mathrm{~kg} / \mathrm{m}^{3}$ apresentou a capacidade de inibir o crescimento de S.aureus, B.cereus, L.monocytogenes, L.innocua e A. hydrophila, apesar de não conseguir a mesma eficácia contra C. fimi, E.coli, P. aeruginosa e S. Enteritidis. Contudo, os autores observaram que a combinação do extrato do resíduo com tratamentos térmicos em condições de pasteurização é possível reduzir a resistência térmica de L.monocytogenes, potencialmente permitindo a redução das condições de tempo-temperatura para a conservação térmica de alimentos. Girardi e colaboradores (2019) não observaram atividade antimicrobiana de bagaço de cana-de-açúcar na concentração de $10 \mathrm{~kg} / \mathrm{m}^{3}$ contra L.monocytogenes, L.innocua, S.aureus, E.coli e S. enterica Enteritidis.

É de conhecimento da comunidade científica que as matrizes alimentares com concentrações altas de polifenóis e compostos derivados atuam na inibição bacteriana como em E. coli, L. monocytogenes, B. cereus, S. aureus, Salmonella spp., além de fungos filamentosos e leveduras importantes para a cadeia agroindustrial (CAXAMBÚ et al., 2016; SANT'ANNA et al., 2017; TROJAIKE et al., 2018; GIRARDI et al., 2019). Sagdic e colaboradores (2011), utilizando extrato fenólico de uvas da variedade Gamay em testes in vitro, observaram grande inibição de $Z$. rouxii e Z. bailii, importantes fungos fitopatogênicos. Os mesmos autores demonstrou inibição do crescimento de Enterobacteriaceae, S. aureus, Salmonella, leveduras e bolores na carne bovina rissóis durante $48 \mathrm{~h}$ de armazenamento a $4{ }^{\circ} \mathrm{C}$, do extrato etanólico de bagaço de uva a $10 \%$, indicando que o bagaço pode ser uma boa opção para estender o prazo de validade de produtos alimentícios. Dependendo dos métodos de extração ou variedades de uva, extratos de bagaço de uva têm atividade antioxidante ou pró-oxidante (NASSIRI-ASL \& HOSSEINZADEH, 2016).

Kołodziejczyk e colaboradores (2013) relataram a capacidade antioxidante e atividade antimicrobiana do extrato de bagaço de cereja azeda industrial, que possuem como componente majoritário os flavonóis, contra Salmonella , E. coli O157:H7 e Listeria spp. O crescimento de 
Salmonella e E. coli O157:H7 foi reduzido em concentrações superiores a $2500 \mu \mathrm{g} / \mathrm{mL}$ e inibido em Listeria spp. Resultados similares foram encontrados por Sant'Anna e colaboradores (2017) ao avaliar extratos aquosos de borra de café. Quando testado diretamente nos alimentos, resultados positivos de inibição microbiana foram identificados estando a mesma relacionada aos polifenóis.

Esses trabalhos creditam a capacidade de inibir o crescimento de importantes microrganismos importantes para a cadeia produtiva de alimentos à presença de fenólicos e óleos essenciais. Deve-se destacar, que os compostos fenólicos e os óleos essenciais possuem atividade antibacteriana, antioxidante e antifúngica contra uma ampla gama de microrganismos através de vários mecanismos (SAGDIC et al., 2011; KHORSHIDIAN et al., 2018). Os mecanismos de ação antibacteriana dos compostos fenólicos ainda não foram totalmente esclarecidos, mas esses compostos são conhecidos por envolver muitos locais de ação no nível celular. Segundo Bouarad-Chibane e colaboradores (2019), muitas referências explicam que essa atividade está relacionada pela modificação da permeabilidade das membranas celulares, mudanças em várias funções intracelulares induzidas pela ligação de hidrogênio dos compostos fenólicos às enzimas ou pela modificação da rigidez da parede celular com perdas de integridade devido a diferentes interações com a membrana celular.

Vários são os motivos que podem justificar a ausência de atividade inibitória dos extratos obtidos de resíduos alimentares, sendo esta relacionada a baixa concentração de compostos nos extratos ou ineficiência do modo de extração e até mesmo de separação fenólicos específicos (CAXAMBÚ et al., 2016). Além disso, alguns fungos como Aspergillus niger e Penicillium sp. podem crescer na presença de taninos, utilizando esses compostos como fonte de carbono ou devido à produção de enzimas hidrolisantes de polifenóis (SCALBERT, 1991; SERRANO et al., 2009).

A atividade antimicrobiana de frutas que contém antocianinas provavelmente é causada por múltiplos mecanismos e sinergismos, pois contêm vários compostos, incluindo ácidos orgânicos fracos, ácidos fenólicos e suas misturas em diferentes formas químicas (CISOWSKA et al., 2011; VERRUCK et al., 2018). Atividade antimicrobiana do ácido p-cumárico contra $E$. coli, S. typhimurium e S. dysenteriae foi relatada por Lou e colaboradores (2012), pois observaram que este composto altera a permeabilidade da membrana celular e tem a capacidade de se ligar ao DNA inibindo a função celular. Ácidos gálico e ferúlico atuam, diferentemente do ácido p-cumárico, desestabilizando a membrana citoplasmática das células de bactérias patogênicas como E. coli, L. monocytogenes, P. aeruginosa e S. aureus (BORGES et al., 2013). 
Os ácidos fenólicos mudaram os componentes polares, apolares e aceitadores de elétrons das células bacterianas. A capacidade de aceitador de elétrons, após exposição a ácido gálico e ácido ferúlico, aumentou para as bactérias Gram-positivas e diminuiu para as Gramnegativas. Isso revela que os ácidos são produtos eletrofílicos e parecem interagir significativamente com os componentes da superfície bacteriana (BORGES et al., 2013). Isso pode se comprovar no estudo de Molva (2015), que analisou a atividade antibacteriana do extrato de semente de uva em células vegetativas e endósporos de Alicyclobacillus acidoterrestris DSM 3922 em suco de maçã. Em análise de microscopia eletrônica de varredura foi visualizado, pela autora, danos à estrutura e aos componentes celulares da bactéria no seu estado vegetativo. No entanto, a atividade antibacteriana contra os endósporos dependia do meio de esporulação.

No estudo realizado por Nohynek e colaboradores (2006) foi proposto que compostos fenólicos têm sua atividade antimicrobiana em bactérias Gram-negativas pelo poder quelante de cátions divalentes de suas membranas externas. Em bactérias Gram-positivas, acredita-se que taninos podem reagir e inibir a biossíntese com componentes da parede celular (JONES et al., 1996). Taninos com potencial ação bacteriana, fúngica e viricida foram isolados de plantas e/ou componentes da planta que contêm atividades antimicrobianas, e que estão comercialmente disponíveis para os consumidores (KHAMENEH et al., 2019). No mesmo contexto, Widsten e colaboradores (2014) identificaram extratos à base de plantas que suprimiu efetivamente as principais bactérias de deterioração de peixes e carne de cordeiro resfriados e relacionou tal capacidade a compostos com alta atividade antioxidante como taninos.

Em relação aos óleos essenciais, a literatura indica basicamente o uso de cascas de frutas cítricas como fonte de compostos antimicrobianos a partir de resíduos agroindustriais. Caputo e colaboradores (2018), ao avaliar extratos aquosos assistidos por micro-ondas de casca de limão, laranja e cidra, observaram que as infusões foram capazes de inibir o crescimento da fase lag de crescimento de linhagens de E. coli, P. fluorescens, P. putida, S. epidermidis, apesar de não mostrarem atividade bactericida contra as bactérias estudadas. Além disso, os autores observaram que esses extratos foram capazes de reduzir a capacidade de formação de biofilme por parte desses microrganismos em testes in vitro. Essas atividades foram relacionadas pelos autores devido à presença de óleos essenciais e polifenóis extraídos dos resíduos.

Extratos de óleos essenciais alcoólicos da casca crua de bergamota-ponkan, pomelo e limão-bergamota não foram seletivos quanto ao tipo de parede celular bacteriana, apresentando atividade antimicrobiana contra E. coli, S. aureus, P. aeruginosa e E. faecalis (GERHARDT et al., 2013). Cabe destacar ainda, que as cascas frescas são fontes mais promissoras que os 
resíduos secos para obtenção de compostos com tal atividade. Casquete e colaboradores (2015), ao analisarem a atividade antimicrobiana de extratos obtidos de tangerina, limão e laranja por ultra alta pressão, mostraram que as infusões, com concentrações de ao menos $1 \mathrm{mg} / \mathrm{mL}$ apresentaram a habilidade de inibir o crescimento de bactérias Gram-positivas e negativas ( $E$. faecalis, B. subtilis, S. aureus, C. sporogenes, Klebsiella, S. Typhimurium, A. lwoffii, A. junii). Extrato de casca de limão e tangerina não apresentaram capacidade antimicrobiana contra linhagens de L.monocytogenes e E.coli e contra linhagens de L.monocytogenes, A. baumannii e Pseudomonas spp., respectivamente. Compostos da casca de laranja doce não foram eficazes contra a linhagem de L. monocytogenes 3391 e Klebsiella spp.

Os mecanismos de ação dos óleos essenciais ainda não foram completamente estabelecidos. No entanto, estudos indicaram que compostos de diferentes grupos químicos presentes nesses produtos naturais são capazes de atuarem em mais de um alvo na célula, como na permeabilização ou ruptura da membrana citoplasmática, permitindo a passagem de compostos não específicos ou liberação do conteúdo citoplasmático (ZHANG et al., 2016). Para Negro e colaboradores (2016), a maior fração de compostos voláteis de óleos essenciais de citrus é constituída por monoterpenos e sesquiterpenos, bem como seus derivados oxigenados. Ainda, há a presença nessas frutas de aldeídos (citral), álcoois e ésteres, compostos não voláteis, que podem agir como composto inibidor de bactérias (NEGRO et al., 2016).

Também, em frutas cítricas deve-se considerar a presença de limoneno, um hidrocarboneto cíclico hidrofóbico, como outros terpenos e terpenóides, cuja atividade antibacteriana é creditada principalmente à sua interação com as membranas celulares (BAKKALI et al., 2008). O limoneno se acumula na membrana citoplasmática, por causa do alto valor do coeficiente de partição nessa estrutura biológica, e altera a lipoestrutura e a fluidez dessa estrutura, que se torna mais permeável. Consequentemente, o material celular pode ser perdido, os lipídios e as proteínas podem sofrer alternâncias celulares (NEGRO et al., 2016). Dannenberg e colaboradores (2019) analisaram óleo essencial de pimenta rosa (Schinus terebinthifolius Raddi), que possui como componente majoritário $\beta$-mirceno (41\%), e observaram alterações na permeabilidade e integridade da membrana celular de todas as bactérias Gram-positivas e Gram-negativas, indicando que o dano à parede celular é um dos seus mecanismos de ação. Ainda, há de se considerar na extração de compostos de resíduos de alimentos a presença de ácidos orgânicos que podem apresentar atividade antimicrobiana ou agir em sinergismo com os compostos estudados e creditados até o presente momento (KIM e RHEE, 2015). Mais estudos são necessários para elucidar de forma completa os modos de ação de agentes antimicrobianos de resíduos agroindustriais. 
Apesar do real potencial de utilização desses extratos como bioconservantes em alimentos, eles ainda apresentam algumas limitações tecnológicas a serem avaliadas e estudadas em sistemas alimentares reais. Antocianinas são um dos polifenóis com tal capacidade. Contudo, elas podem ser degradadas por enzimas naturalmente presentes em alimentos como a polifenoloxidase (RUENROENGKLIN et al., 2009), o que pode ser um grande limitante para alimentos que necessitam armazenamento a longo prazo. Ainda, sobre o mesmo composto, são susceptíveis a variações de pH, culminando em sua degradação, alteração molecular e redução de atividades biológicas (CISOWSKA et al., 2011).

Em relação aos óleos essenciais devemos considerar que podem ser oxidados e sofrer modificações que alterem sua atividade ao longo do armazenamento. Um bioconservante natural para ter sua produção e utilização em larga escala deve apresentam amplo espectro de ação, mas também deve apresentar estabilidade e flexibilidade de utilização. Extratos com base em antocianinas, por exemplo, teriam limitação de aplicação em alimentos levemente ácidos devido à redução de sua estabilidade (LACOMBE et al., 2010).

Um outro ponto de grande importância e que deve ser considerado é a necessidade de se explorar mais aspectos de risco para utilização desses extratos em alimentos. Moncalvo e colaboradores (2016) analisaram o conteúdo de contaminantes químicos: ocratoxina A, aminas biogênicas, pesticidas e metais em extratos de cascas de uvas de diferentes vinícolas localizadas no norte da Itália. Ocratoxina foi detectada em baixas concentrações nos pós das cascas e nos extratos de algumas variedades, por exemplo. Além das questões extrínsecas relacionadas às uvas, ainda devem ser considerados os aspectos toxicológicos relacionados à ingestão excessiva de polifenóis da fruta. A ingestão excessiva de certos flavonóides alcançada através da suplementação de extratos vegetais pode ter efeitos potencialmente tóxicos no organismo (BOUŠOVA e SKALOVA, 2012).

Soma-se a esses fatores, a falta de protocolos e equipamentos industriais testados e concisos para processamento de subprodutos, e isso pode ser uma barreira adicional à sua adoção, questão recorrente em inovações e desenvolvimento de produtos. Além dos custos operacionais, a implementação de uma unidade de processamento de subprodutos alimentícios deve abordar questões legais e sanitárias. Por exemplo, não há legislação ou regulamento técnico de identidade e qualidade para esses produtos que norteiam questões de implantação de uma planta de processamento ou de análises de padrões microbiológicos e físico-químicos. Vários outros pontos podem ser levantados como o custo benefício da extração e processamento desses compostos, o uso verdadeiramente sustentável desses subprodutos, uma vez que, o 
processo de extração pode gerar maior quantidade ou até mesmo resíduos com maior potencial de agressão ambiental, dentre outros.

\section{Conclusões}

Estima-se que a quantidade de resíduos com potencial aproveitamento após o processamento é de milhões de toneladas a cada ano. Dentre os vários fatores, destacam-se o desperdício excessivo, problemas na conservação e falhas na cadeia produtiva levando a perdas e prejuízos financeiros, principalmente de frutas e hortaliças.

De maior importância é o potencial de subprodutos devido ao conteúdo de biocomponentes, que podem ser usados para a produção de alimentos inovadores, fazendo uso de compostos naturais. Os extratos vegetais, principalmente os obtidos de resíduos alimentares, têm grande potencial de serem utilizados como bioconservantes na indústria de alimentos, sendo necessário estudos tecnológicos para a sua aplicação em grande escala.

Devido ao alto teor de componentes bioativos, os subprodutos (casca, polpa, sementes) constituem uma matéria-prima natural valiosa para aplicação em alimentos, como polifenóis, óleos aromáticos, dentre outros. As substâncias extraídas podem ser utilizadas na produção de alimentos como ingredientes funcionais e nutracêuticos, tanto na alimentação humana quanto animal promovendo saúde, ou nas indústrias cosmética e farmacêutica.

A tecnologia moderna de processamento sustentável de alimentos deve ter em mente a necessidade de reduzir o desperdício e usar os subprodutos de forma eficaz. O impacto dessas ações é importante para a economia alimentar atual, bem como para o futuro estado do meio ambiente. Ainda assim, poucos resíduos do processamento de frutas e vegetais são utilizados de forma adequada na indústria de alimentos como novos atrativos através do enriquecimento de ingredientes naturais, na área farmacêutica e na produção de biocombustíveis, merecendo cada vez mais pesquisas e estudos pela comunidade científica e pelas indústrias.

\section{Referências}

ALVARENGA, G. F. Avaliação do potencial antimicrobiano e antioxidante de espécies vegetais para aplicação como aditivo em filmes/revestimentos para alimentos. Orientadora: Pinto, Nísia Andrade Villela Dessimoni. 2018. 131 p. Dissertação de Mestrado - Programa de Pós-Graduação em Ciência e Tecnologia de Alimentos, Universidade Federal dos Vales do Jequitinhonha e Mucuri, Diamantina, 2018.

BAKKALI, F.; AVERBECK, S.; IDAOMAR, M. Biological effects of essential oil: a review. Food and Chemical Toxicology, v.46, n.2, p.446-75, 2008. 
BALDIN, J. C. Avaliação do potencial antimicrobiano e antioxidante do extrato de jabuticaba (Myrciaria cauliflora) microencapsulado adicionado em linguiça frescal e mortadela. Orientador: Trindade, Marco Antonio. 2016. 100f. Dissertação de Doutorado (Programa de Pós-Graduação em Ciências) Faculdade de Zootecnia e Engenharia de Alimentos, Universidade de São Paulo, Pirassununga, 2016.

BOUŠOVÁ, I.; SKÁLOVÁ, L. Inhibition and induction of glutathione S-transferases by flavonoids: possible pharmacological and toxicological consequences. Drug Metabolism Reviews, v.44, n.4, p.267-286, 2012.

BOUARAB-CHIBANE, L.; FORQUET, V.; LANTÉRI, P.; CLÉMENT, Y.; LÉONARDAKKARI, L.; OULAHAL, N.; DEGRAEVE, P.; BORDES, C. Antibacterial properties of polyphenols: characterization and QSAR (Quantitative structure-activity relationship) models. Frontiers in Microbiology, v.10, p.829, 2019.

BORGES, A.; FERREIRA, C.; SAAVEDRA, M.J.; SIMÕES, M. Antibacterial activity and mode of action of ferulic and gallic acids against pathogenic bacteria. Microbial Drug Resistance, $v .19, \mathrm{n} .4, \mathrm{p} .256-265,2013$.

CAETANO, K.S. Utilização de amido, óleo de orégano e extrato de resíduo de abóbora para o desenvolvimento de filmes biodegradáveis ativos. Orientadora: Cladera-Oliveira, Florência. 2016. 122f. Dissertação de Mestrado (Programa de Pós-Graduação em Ciência e Tecnologia de Alimentos), Instituto de Ciência e Tecnologia de Alimentos, Universidade Federal do Rio Grande do Sul, Porto Alegre, 2016.

CAPUTO, L.; QUINTIERI, L.; CAVALLUZZI, M.M.; LENTINI, G.; HABTEMARIAM, S. Antimicrobial and antibiofilm activities of citrus water-extracts obtained by microwaveassisted and conventional methods. Biomedicines, v.6, n.2, 9.70-84, 2018.

CASQUETE, R.; CASTRO, S.M.; MARTÍN, A.; RUIZ-MOYANO, S.; SARAIVA, J.A.; CÓRDOBA, M.G.; TEIXEIRA, P. Evaluation of the effect of high pressure on total polyphenolic content, antioxidant and antimicrobial activity of citrus peels. Innovative Food Science and Emerging Technologies, v.31, p.37-44, 2015.

CAXAMBÚ, S.; BIONDO, E.; KOLCHINSKI, E.M.; LAPPE, R.; BRANDELLI, A.; SANT'ANNA, V. Evaluation of the antimicrobial activity of pecan nut [Carya illinoinensis (Wangenh) C. Koch] shell aqueous extract on minimally processed lettuce leaves. Food Science and Technology (Campinas), v.36, p.42-45, 2016.

CISOWSKA, A.; WOJNICZ, D.; HENDRICH, A. Anthocyanins as antimicrobial agents of natural plant origin. Natural Product Communication, v.6, n.1, p.149-156, 2011.

DALLA COSTA, A.P.; THYS, R.C.S.; RIOS, A.O.; FLORES, S.H. Carrot flour from minimally processed residue as substitute of b-carotene commercial in dry pasta prepared with common wheat (Triticum aestivum). Journal of Food Quality, v.39, p.590-598, 2016.

DANNENBERG, GUILHERME DA SILVA; FUNCK, GRACIELE DAIANA; SILVA, WLADIMIR PADILHA; FIORENTINI, ÂNGELA MARIA; Essential oil from pink pepper (Schinus terebinthifolius Raddi): Chemical composition, antibacterial activity and mechanism of action, Food Control, v. 95, p. 115-120, 2019. 
DIAO, WEN-RUI; HU, QING-PING; ZHANG, HONG; XU，JIAN-GUO; Chemical composition, antibacterial activity and mechanism of action of essential oil from seeds of fennel (Foeniculum vulgare Mill.). Food Control. v. 35, p.109-116, 2014.

FARIAS, L. L.; LOSS, R. A.; SOUSA, S.; PUTON, B. M. S.; PAROUL, N.; CANSIAN, R. L.; GUEDES S. F. Potencial antimicrobiano e avaliação físico-química da casca, polpa e biomassa do noni (Morinda citrifolia Linn). Global Science and Technology, v.11, n.2, p.247-255, 2018.

FRIEDMAN, MENDEL; HENIKA, PHILIP R.; LEVIN, CAROL E.; Bactericidal Activities of Health- Promoting, Food- Derived Powders Against the Foodborne Pathogens Escherichia coli, Listeria monocytogenes, Salmonella enterica, and Staphylococcus aureus. Joural of Foofd Science. v.78 p. 270-275 2013.

GERHARDT, C.; WIEST, J.M.; GIROLOMETTO, G.; SILVA, M.A.S.; WESCHENFELDER, S. Aproveitamento da casca de citros na perspectiva de alimentos: prospecção da atividade antibacteriana. Brazilian Journal of Food Technology, v.31, p.215-2018, 2013.

JONES, R.N. The emergent needs for basic research, education, and surveillance of antimicrobial resistance. Diagnostic Microbiology and Infectious Diseases, v.25, p.153-161, 1996.

KHAMENEH, Bahman et al. Review on plant antimicrobials: A mechanistic viewpoint. Antimicrobial Resistance \& Infection Control, v.8, n.1, p.118, 2019.

KHORSHIDIAN, N.; YOUSEFI, M.; KHANNIRI, E.; MORTAZAVIAN, A. M.; Potential application of essential oils as antimicrobial preservatives in cheese. Innovative Food Science and Emerging Technologies, v.45, p. 62-72, 2018.

KIM, S.A.; RHEE, M.S. Synergistic antimicrobial activity of caprylic acid in combination with citric acid against both Escherichia coli O157:H7 and indigenous microflora in carrot juice. Food Microbiology, v. 49, p.166-172, 2015.

KOŁODZIEJCZYK, K.; SÓJKA, M.; ABADIAS, M.; VIÑAS, I.; GUYOT, S.; BARON, A. Polyphenol composition, antioxidant capacity, and antimicrobial activity of the extracts obtained from industrial sour cherry pomace. Industrial Crops and Products. v.51, p. 279288, 2013.

LACOMBE, A.; WU, V.C.H.; TYLER, S.; EDWARDS, K. Antimicrobial action of the American cranberry constituents: phenolics, anthocyanins, and organic acids, against Escherichia coli O157:H7. International Journal of Food Microbiology, v.139, p.102-107, 2010.

LEOUIFOUDI, I.; HARNAFI, H.; ZYAD, A. Olive mill waste extracts: polyphenols content, antioxidant, and antimicrobial activities. Advances in Pharmacological Sciences, v.2015, p.714138, 2015.

LUCERA, A., COSTA, C., CONTE, A., Del Nobile, M. A. Food applications of natural 1309 antimicrobial compounds. Frontiers in microbiology, v.3, 287, 2012. 
MARCIAL, GUILLERMO E., GEREZA, CARLA L., KAIRUZA, MARTHA NUÑEZ, ARAOZB, VICTORIA COLL, SCHUFFB, CAROLA, VALDEZA, GRACIELA FONT, Influence of oregano essential oil on traditional Argentinean cheese elaboration: Effect on lactic starter cultures. Revista Argentina de Microbiologia, v.48, p. 229-235, 2016.

MOLVA, CELENK; BAYSAL, AYSE HANDAN. Antimicrobial activity of grape seed extract on Alicyclobacillus acidoterrestris DSM 3922 vegetative cells and spores in apple juice. Food Science and Technology. v.60, n.1, p. 238-245, 2015.

MONCALVO, A.; MARINONI, L.; DORDONI, R.; DUSERM GARRIDO, G.; LAVELLI, V.; SPIGNO, G. Waste grape skins: evaluation of safety aspects for the production of functional powders and extracts for the food sector. Food Additives \& Contaminants: Part A, v.33, n.7, p.1116-1126, 2016.

NAGY, M.; SEMENIUC, C.A.; SOCACI, S.A.; POP, C.R.; ROTAR, A.M.; SALAGEAN, C.D.; TOFANA, M. Utilization of brewer's spent grain and mushrooms in fortification of smoked sausages. Food Science and Technology Campinas, v.37, n.2, p.315-320, 2017.

NASSIRI-ASL, M.; HOSSEINZADEH, H. Review of the Pharmacological Effects of Vitis vinifera (Grape) and its Bioactive Constituents: An Update. Phytotherapy Research, v.30, n.9, p.1392-1403, 2016.

NEGRO, V.; MANCINI, G.; RUGGERI, B.; FINO, D. Citrus waste as feedstock for bio-based products recovery: Review on limonene case study and energy valorization. Bioresource Technology, v.214, p.806-816, 2016.

NOHYNEK, L.J.; ALAKOMI, H.L.; KÄHKÖNEN, M.P.; HEINONE, M.; HELANDER, I.M.; OKSMAN-CALDENTEY; PUUPPONEN-PIMIÄ, R. Berry phenolics: antimicrobial properties and mechanisms of " action against severe human pathogens. Nutrition and Cancer, v.54, p.18-32, 2006.

PANTELIĆ, MM, DABIĆ ZAGORAC, D. Č., DAVIDOVIĆ, SM, TODIĆ, SR, BEŠLIĆ, ZS, GAŠIĆ, UM, TEŠIĆ, Ž. LJ. \& NATIĆ, MM. Identification and quantification of phenolic compounds in bark, pulp and berry seeds in 13 vine varieties grown in Serbia. Food Chemistry, v.211, p.243-252. 2016.

ROCHA, A. J. A. C. Avaliação do Potencial Antimicrobiano do Extrato da Acerola. Orientador: Poletto, Patrícia. 2019. 54f. Trabalho de Conclusão de Curso (Engenharia de Alimentos) - Departamento de Engenharia Química e Engenharia de Alimentos, Universidade Federal de Santa Catarina. Florianópolis, 2019.

RUENROENGKLIN, N.; SUN, J.; SHI, J.; XUE, S.J.; JIANG, Y. Role of endogenous and exogenous phenolics in litchi anthocyanin degradation caused by polyphenol oxidase. Food Chemistry, v.115, p.1253-1256, 2009.

SCALBERT, A. Antimicrobial Properties of Tannins. Phytochemistry, v.30, n.12, p.38753883, 1991.

SAGDIC, O.;OZTURK, I.;OZKAN, G.;YETIM, H.;EKICI, L.; YILMAZ, M. T. RP-HPLC$\mathrm{DAD}$ analysis of phenolic compounds in pomace extracts from five grape cultivars: evaluation 
of their antioxidant, antiradical and antifungal activities in orange and apple juices. Food Chemistry, v.126, n.4, p.1749-1758, 2011.

SANT'ANNA, V.; BIONDO, E.; KOLCHINSKI, E.M; SILVA, L.F.S.; CORREAA, A.P.F.; BACH, E.; BRANDELLI, A. Total Polyphenols, Antioxidant, Antimicrobial and Allelopathic Activities of Spend Coffee Ground Aqueous Extract. Waste and Biomass Valorization, v.8, p.439-442, 2017.

SANTOS, T.R.J.; DE AQUINO SANTANA, L.C.L. Potencial antimicrobiano de diferentes extratos da casca de mirtilo (Vaccinium myrtillus). Anais do $7^{\text {th }}$ International Symposium on Technological Innovation-ISTI 2016. 2016.

SERRANO, J.; PUUPONEN-PIMIA, R.; DAUER, A.; AURA, A.M.; SAURACALIXTO, F. Tannins: current knowledge of food sources, intake, bioavailability and biological effects. Molecular Nutrition and Food Research, v.53, p.310-329, 2009.

TROJAIKE, G.H.; BIONDO, E.; LAPPE, R.P.; BRANDELLI, A.; SANT'ANNA, V. Antimicrobial Activity of Araucaria angustifolia Seed (Pinhão) Coat Extract and its Synergism with Thermal Treatment to Inactivate Listeria monocytogenes. Food and Bioprocess Technology, v.12, p.193-197, 2019.

VERRUCK, S.; PRUDENCIO, E.S.; DA SILVEIRA, S.M. Compostos bioativos com capacidade antioxidante e antimicrobiana em frutas. Revista do Congresso Sul Brasileiro de Engenharia de Alimentos. 2018.

WIDSTEN, P.; CRUZ, C.D.; FLETCHER, G.C.; PAJAK, M.A.; MCGHIE, T.K. Tannins and Extracts of Fruit Byproducts: Antibacterial Activity against Foodborne Bacteria and Antioxidant Capacity. Journal of Agricultural and Food Chemistry, v.62, p.11146-11156, 2014.

ZAMBRANO, CAROLINA; KEREKES, BEÁTA; KOTOGÁN; ALEXANDRA; PAPP, TAMÁS; VÁGVOLGYI, CSABA; KRISCH, JUDIT; TAKÓ, MIKLÓS. Antimicrobial activity of grape, apple and pitahaya residue extracts after carbohydrase treatment against foodrelated bacteria. LWT-Food Science and Technology, v. 100, p. 416-425, 2019.

ZHANG, Y. et al. Antibacterial activity and mechanism of cinnamon essential oil against Escherichia coli and Staphylococcus aureus. Food Control, v.59, p.282-289, 2016.

ZHU, F.; DU, B.; ZHENG, L.; LI, J. Advance on the bioactivity and potential applications of dietary fibre from grape pomace. Food Chemistry, v.186, p.207-2012, 2015. 